\title{
Effects of computer-based training on children's executive functions and academic achievement
}

\author{
Pedro Javier Conesa ${ }^{1}$, Jon Andoni Duñabeitia ${ }^{2,3}$ \\ ${ }^{1}$ Facultad de Educación, Universidad de Murcia, Murcia, Spain. \\ ${ }^{2}$ Centro de Investigación Nebrija en Cognición, Universidad Antonio de Nebrija, Madrid, Spain. \\ ${ }^{3}$ The Arctic University of Norway, Tromsø, Norway.
}

\begin{abstract}
Authors' Note
Pedro Javier Conesa https://orcid.org/0000-0003-0679-6161

Jon Andoni Duñabeitia https://orcid.org/0000-0002-3312-8559
\end{abstract}

The authors declare that they have no known conflict of interest to disclose.

This research has been partially funded by grants PGC2018-097145-B-I00 and RED2018-102615608 T from the Spanish Government and H2019/HUM-5705 from the Comunidad de Madrid.

Correspondence concerning this article should be addressed to Pedro Javier Conesa, Faculty of Education, University of Murcia, Murcia 30100, Spain. Email: pj.conesacervera@um.es 


\begin{abstract}
The educational community is deeply interested in knowing how to improve the academic performance of its students. And in particular, with regard to the skills critical to academic performance, the literature has revealed that the development of executive functions (EF) plays a key role. Although numerous studies have aimed to improve EF through computerized cognitive training interventions, the evidence of the effect derived from these interventions remains ambiguous. The purpose of this study is to investigate the effects of a computerized game-based training program on EF and its impact on academic performance in 713 Spanish Primary School students $(\mathrm{M}=10.2$ years old, $51.3 \%$ girls $)$. The EF training was carried out in 26 participating schools ( 8 weeks, 3 sessions of 15-20 minutes each week), measuring both before and after the training students' executive functions through questionnaires and chronometric tests, and obtaining information on academic performance. The results showed an improvement within the training group in the validated questionnaires exploring inhibition and working memory, as well as in academic performance, compared to the control group. In contrast, no significant intergroup differences were observed in the chronometric tests measuring inhibition. These results highlight the relevance of computerized EF training programs as part of the educational activities developed at schools.
\end{abstract}

Keywords: computer-based training, executive functions, inhibition, working memory, academic achievement, elementary school students 


\section{Effects of computer-based training on children's executive functions and academic achievement}

Topics such as scholastic success or failure have generated interest from numerous researchers who share a common goal: improvement in academic performance (Balkis, 2018). Academic performance is shown through the abilities, skills, knowledge, and attitudes developed by students in the teaching-learning process, and as has been observed in recent decades, knowledge of cognitive mechanisms in childhood can be essential to understand how this process develops (Rosen et al., 2018).

In particular, with regard to the skills that are critical for academic success, research has revealed that the development of executive functions (EF hereafter) plays a fundamental role (Diamond, 2013; Cortés et al., 2019). These executive functions have proven to be a key element in the development of skills in language and mathematics, as well as in the processing and organization of information received (Blair \& Raver, 2015; Blair \& Razza, 2007; Diamond \& Ling, 2019; G. J. Duncan et al., 2007; Sesma et al., 2009; Zelazo \& Carlson, 2012). Executive functions are understood as those neurocognitive mechanisms that control thoughts and behaviors aimed at achieving a goal or objective (Diamond, 2013). Within the complexity of the construct, it seems that there is a general consensus that there are three principal concepts at the core of EF: inhibition, cognitive flexibility, and working memory (Diamond, 2013; Miyake et al., 2000). From these other mechanisms emerge which are also essential for students, such as reasoning, problem solving, and planning.

Inhibition (also known as inhibitory control) refers to the ability to inhibit predominant or automated responses and do instead what is most appropriate or necessary. There are two main subcomponents of inhibitory control: response inhibition and interference control. Response inhibition involves controlling conduct and emotions in one's own behavior, suppressing a dominant response (for example, persisting in a task even though there is a temptation to quit). Controlling interference involves controlling attention and thoughts, resisting distractions in the environment (such as those present in the classroom), and maintaining concentration (Diamond, 2020). Several studies suggest that inhibitory control in the early stages of an individual's life can 
predict outcomes and success throughout life. For example, in a 32-year longitudinal study, Moffitt et al. (2011) found that children aged 3 to 11 years with better inhibitory control were more likely to continue studying in adolescence, were less likely to make risky decisions, had a healthier lifestyle, and had a greater perception of happiness in adulthood. On the other hand, cognitive flexibility is defined as the ability to switch between different mindsets, tasks, or goals. This executive function helps students to manage fluid strategies that allow them to adapt to unexpected situations by thinking without rigidity and freeing themselves from inefficient automatisms (Diamond, 2013). Finally, working memory involves maintaining and using information appropriately even if it is not perceptually present (Baddeley \& Hitch, 1994; Kent, 2016). That is, it is the cognitive ability that allows students to actively retain information while mentally working on that content or on any other (Engle \& Kane, 2004; D'Esposito \& Postle, 2015).

It has been suggested that each component of EF develop at their own pace throughout childhood and adolescence, reaching maturity at different ages (Ferguson et al., 2021). This prolonged development is associated with changes in the prefrontal cortex (Gogtay et al., 2004). The 6 to 12year-old stage is crucial in the development of EF (Davidson et al., 2006; Ferguson et al., 2021), since neuronal plasticity is particularly high and the prefrontal cortex is especially sensitive to environmental influences (Bull et al., 2011). However, there is no general consensus on the specific age at which they typically reach their exact maturity and therefore, various authors suggest using different approaches and tasks to assess EFs (Miyake \& Friedman, 2012; Zelazo et al., 2014). As a consequence, several authors have discussed the weak links between the different tasks used to measure $\mathrm{EF}$ and their respective measured factors, concluding that the tasks represent a dissociable measurement of capabilities (fractional EF theory) rather than a general construct (Ferguson et al., 2021; Miyake et al., 2000; Miyake \& Friedman, 2012).

It is more than obvious to think that students who have the ability to act in the classroom in a thoughtful way, or who are able to stay focused despite distractions, have a greater chance of academic success. In fact, it has been demonstrated that interventions that improve executive functions result in notable improvement in these behaviors or actions (Diamond \& Lee, 2011; Diamond \& Ling, 2019; Kassai et al., 2019). Several authors have shown that when the inhibitory demand is reduced in certain tasks, students have an easier time solving those tasks (Cassotti et al., 2016; Houdé \& Borst, 2015; Lubin et al., 2013). Along these lines, a meta-analysis carried out 
by Yeniad et al., (2013) showed that cognitive flexibility was a significant predictor for math and reading skills in students between 4 and 13 years old, demonstrating the close relationship between EFs and academic performance. Also, various findings have suggested that interventions based on the improvement of EFs can reduce the gap of socioeconomic status (SES) and academic performance (Bierman et al., 2008; Raver et al., 2011), since the SES correlates with the EF skills during the early years of life (Hackman et al., 2015; Last et al., 2018).

Given that EF are subject to significant development throughout childhood and, as we have seen, they are significant predictors of many outcomes associated with learning, success, or academic performance (Karbach \& Unger, 2014; Schwaighofer et al., 2015; Titz \& Karbach, 2014), numerous studies have been aimed at improving EF through cognitive training interventions (Diamond \& Ling, 2019). With respect to the transfer that can be derived from this type of training, the evidence is ambiguous (Pandey et al., 2018; Smid et al., 2020). Although some studies have shown positive effects of these training programs on academic performance (Diamond \& Ling, 2019; Raver et al., 2011), others have not found significant effects (Morris et al., 2013). However, the findings found in different empirical studies and meta-analyses show evidence that training programs have a stronger effect in children than in adults (Karbach \& Unger, 2014; Oberste et al., 2019; Zhao et al., 2018), reinforcing the idea that it is possible to improve cognitive skills and academic performance at school through computerized interventions.

In today's world of digitization, computerized training seems to be a great ally for the development of EF in middle childhood. Computerized EF training is defined as an intervention that uses a tablet, computer, or smartphone to carry out either conventional EF tasks (traditional or direct method) and/or electronic programs with game elements in order to improve EF (indirect method). The traditional method refers to training programs that use traditional cognitive tasks (Stroop, Flankers, Simon, N-back Task, Dimensional Change Card Sort, etc.) to improve children's cognitive abilities (e.g., Espinet et al., 2013). Unlike this method, game-based training uses different sensory stimuli (sounds, color, movement), providing immediate and precise feedback. In addition, they often use a narrative with animated characters, interactive environments, and information on the level of progress which is visible to the user at all times. These characteristics can make this type of task more interesting in its playability (Prins et al., 2013) and increase the intrinsic interest of children in carrying out the training (Ryan \& Deci, 2000). 
A recent meta-analysis of 36 studies carried out by Cao et al., (2020) showed that computerized training had a moderate effect in improving children's EF, especially in working memory, which was significantly higher after training. In spite of this, it is worth mentioning that the debate about the controversy regarding the effects of this type of trainings remain open. Some studies demonstrated that computerized training was found to be effective for working memory improvement (Klingberg, 2010; A. B. Morrison \& Chein, 2011; Spencer-Smith \& Klingberg, 2015), while others found the effect to be negligible (Melby-Lervåg et al., 2016; Wong et al., 2014). Similar results occur with inhibition or flexibility, where contradictory results in the transfer effect of these programs have been also found (Ackermann et al., 2018; Espinet et al., 2013; Sánchez-Pérez et al., 2018; Spierer et al., 2013; Weerdmeester et al., 2016). Nonetheless, it should be noted that many studies have claimed that the effects of these computerized training programs transcend the concept of EF itself, impacting general issues such as students' academic performance (Sánchez-Pérez et al., 2018).

Given the importance of academic performance, the prospect of being able to improve it through computerized cognitive training has great practical relevance. However, the lack of empirical studies that analyze the effect and transfer of these training programs (especially, carried out in the school context itself) on the academic performance of Primary Education students makes it necessary to carry out research in this line. Hence, the purpose of this study is to investigate the effects and moderators of a computerized game-based training program on the EFs and academic performance of a broad group of Primary Education students. Thus, this study aims to analyze the effects of computerized game-based training on the EFs of children aged 8 to 13 years old, and to explore the impact of the intervention on their academic performance. To this end, the study followed a longitudinal design with three phases (pre-test, training, and post-test) and with two groups (control and experimental).

\section{Method}

\section{Participants}


The recruitment of the sample was carried out through contact via email with public and private schools in different Spanish provinces, and through dissemination via social networks (Twitter and Facebook). All of the teachers (with the consent of the respective management team) who showed interest in having their classes participate received all the information and a registration form. Finally, 26 schools confirmed their participation, with a total of 54 groups of 4 th, $5^{\text {th }}$, and $6^{\text {th }}$ grade of Primary Education. Groups were randomly selected for group assignment (control or experimental).

In this experimental study, the participants were 713 Primary Education students aged between 8 and 13 years old $(\mathrm{M}=10.2, \mathrm{SD}=0.88,51.3 \%$ girls $)$ from 26 Spanish public and private schools. The control group included 331 students $(\mathrm{M}=10.2$ years, $\mathrm{SD}=0.91 ; 51 \%$ girls $)$ and the experimental group 382 students $(\mathrm{M}=10.1$ years, $\mathrm{SD}=0.86 ; 52 \%$ girls $)$. Regarding the grade level, 31\% were from $4^{\text {th }}$ of Primary Education, $40 \%$ from $5^{\text {th }}$ of Primary Education, and $29 \%$ from $6^{\text {th }}$ of Primary Education.

Although the initial sample was slightly larger, children with special educational needs $(\mathrm{N}=88)$, those who did not start the program intervention due to confinement or personal problems $(\mathrm{N}=$ $41)$, those who did not undertake the post-test measurement $(\mathrm{N}=35)$ and, finally, those students of the experimental group who did not reach the objective set a priori of 15 completed training sessions $(\mathrm{N}=21)$ were excluded from the analysis.

The project was approved by the Research Ethics Board of the University of Murcia (Ref: 2989/2020). As the sample consisted of underage participants, families were asked to sign an informed consent form. Students were informed that their responses would be confidential and used for research purposes only. Participation in the study was voluntary and students could withdraw at any time.

\section{Procedure}

\section{Timeline}


The initial evaluation (pre-test) began in January 2021 and was carried out over 3 weeks with all groups (see Figure 1 for a schematic representation). At the end of this phase, the intervention for the experimental group began for the next 8 weeks. One week after finishing the training, the students of both groups were evaluated again (post-test). The pre-test and post-test moments coincided with the academic evaluations at the beginning (January 2021) and at the end of the term (April). At the end of the measurements, the control group was offered the option of completing the cognitive stimulation program under the same conditions as the experimental group had initially done so that they could thus benefit from its possible usefulness.

Figure 1. Timeline of the project.

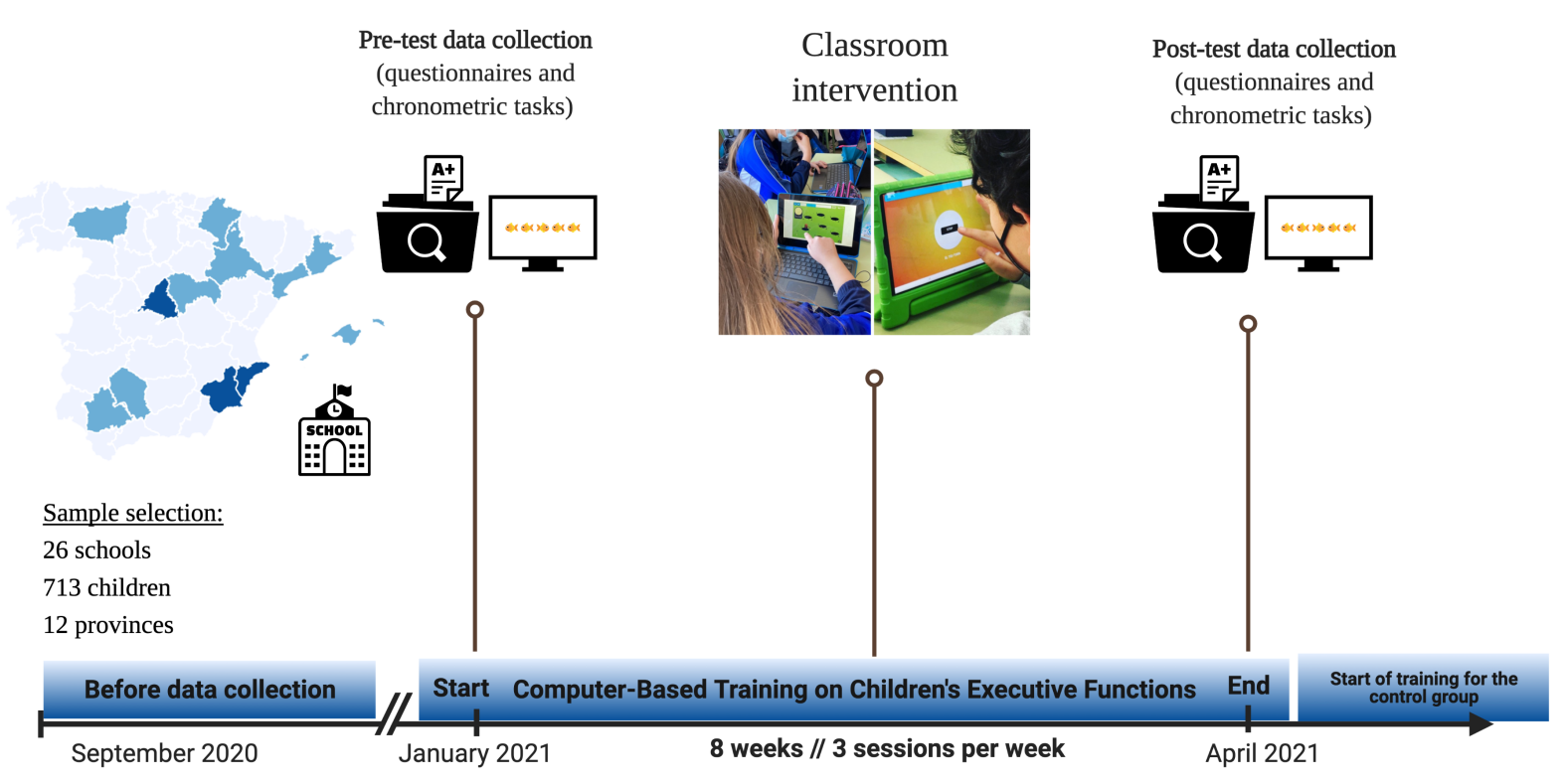

\section{Pre-test and Post-test tasks and questionnaires}

The Spanish version of The Childhood Executive Function Inventory (CHEXI; Catale et al., 2015) was used. This instrument was completed by the families. It consists of 24 items and assesses four aspects of the students' executive functioning (working memory, planning, regulation, and inhibitory control), resulting in two final scales: working memory and inhibition. Previous studies 
have shown that the CHEXI has good internal consistency and factorial structure as well as good predictive capacity on school performance (Thorell et al., 2013). The items are described in an inverted way where it is established that a lower score of the participant in the corresponding subscales means better levels of EF.

Flanker task. This performance test is well known for evaluating the ability to inhibit irrelevant stimuli (Eriksen \& Eriksen, 1974). Continuing with the version adapted to the child population of this task (see Rueda et al., 2004; Antón et al., 2014), the students had to press the key that corresponded to the direction the central fish was looking at, ignoring the other surrounding fish (on the flanks). The fish could point in the same direction as the other fish (congruent condition) or in the opposite direction (incongruous condition). If the central fish was looking to the left, the participant had to press the X key on the keyboard; if the fish looked to the right, the participant would need to press the letter M. After a short, guided training of 4 trials (two trials per condition), 40 trials (20 per condition) were randomly presented. A warning cross of $500 \mathrm{~ms}$ duration preceded the stimulus, which was kept on screen for a maximum time of $1500 \mathrm{~ms}$. After the stimulus, the screen was blank for $500 \mathrm{~ms}$. Response times for each trial and correctness of responses were recorded. Participants completed this task through the Gorilla Experiment Builder platform (Anwyl-Irvine et al., 2020).

Simon task. In this classic task (Simon \& Rudell, 1967), participants saw a red circle or blue square on one side of the computer screen. If the stimulus presented was a red circle, they should press the X key; if the stimulus were a blue square, they would need to press the M key. This task includes congruent and incongruous conditions depending on the coincidence between the expected response for each stimulus and the place of appearance of the stimuli on the screen (e.g., congruent: circle red on the left side of the screen or blue square on the right side of the screen; incongruous: red circle on the right side of the screen or blue square on the left side of the screen). After a short, guided training of 4 trials (two per condition), 30 randomized trials ( 15 per condition) were presented. In each trial, a $500 \mathrm{~ms}$ long warning cross preceded the stimulus, which remained on the screen for $1500 \mathrm{~ms}$. After the stimulus, the screen was blank for $500 \mathrm{~ms}$.

Academic performance was estimated from the grades obtained in the corresponding quarters of the academic year. The end of the first quarter coincided with the pre-test measurement (December 
2020) and the end of the second quarter (April 2020) with the post-test measurement. Numerical grades were obtained for the subjects of Language and Literature, Mathematics, Social Sciences, and Natural Sciences with numerical values from 1 (insufficient) to 10 (excellent), where 5 represents the minimum value to pass.

\section{The computer-based training program (CTP)}

The computerized training program (CTP) chosen was CogniFit (CogniFit Inc., San Francisco, CA, USA), a program that has been scientifically validated in various populations (Kraus \& Breznitz, 2009; Peretz et al., 2011; Preiss et al., 2013; Shatil, 2013; Shah et al., 2017). This system allows a personalized adaptation of the training program through an initial cognitive assessment (Cognitive Assessment Battery, CAB) whose results determine the content and level of subsequent training (see Tapia \& Duñabeitia, 2021). The training program is based on 34 different games with visual, auditory, and cross-modality stimuli, designed with the purpose of training a wide range of cognitive processes but focused on enhancing EF. The program was designed to be integrated into the school routine with the support of the teachers. Teachers received a brief, 30-minute initial training in order to familiarize themselves with the program. Each class had to do 3 sessions per week (preferably on alternate days) for 8 weeks. Each session included 3 games and lasted approximately 15-20 minutes. A minimum of 14 sessions was established as the objective to be achieved in order to complete the training program. Performance was automatically recorded and uploaded to a server where researchers could confirm compliance. Tutors received information by email or phone once every 2-3 weeks.

\section{Results}

To complete the statistical analysis of this study, the open-source statistical software Jamovi v.1.6 (Jamovi project; jamovi.org) was used. Descriptive analyses were completed first. The mean scores and standard deviations for both groups are shown in Table 1. Next, a series of repeated measures analysis of variance (ANOVAs) were performed to identify if there were differences in each group between the pretest and posttest, in addition to knowing if there is interaction between the group and the time of the evaluation. 
Table 1. Mean scores by group in the pre-test and post-test.

\section{Training Group Control Group}

\begin{tabular}{|c|c|c|c|c|}
\hline & Pre-test & Post-test & Pre-test & Post-test \\
\hline \multicolumn{5}{|l|}{ CHEXI Scores } \\
\hline Working Memory & $29.9(9.14)$ & $28.5(9.19)$ & $28.2(8.67)$ & $28.6(8.70)$ \\
\hline Inhibition & $29.8(7.33)$ & $28.3(7.13)$ & $29.5(7.31)$ & $29.0(7.36)$ \\
\hline \multicolumn{5}{|l|}{ Flankers Task } \\
\hline Error rates - congruent & $5.94(14.1)$ & $7.57(14.5)$ & $5.94(11.8)$ & $6.63(13.5)$ \\
\hline Error rates - incongruent & $25.5(34.3)$ & $26.8(33.6)$ & $30.7(36.1)$ & $28.7(36.4)$ \\
\hline Reaction times - congruent & $773(237)$ & $698(238)$ & $746(229)$ & 704 (199) \\
\hline Reaction times - incongruent & $867(391)$ & $821(440)$ & $912(491)$ & $833(447)$ \\
\hline \multicolumn{5}{|l|}{ Simon Task } \\
\hline Error rates - congruent & $5.50(11.8)$ & $5.70(9.94)$ & $7.33(13.7)$ & $5.64(11.4)$ \\
\hline Error rates - incongruent & $12.8(20.0)$ & $10.9(15.8)$ & $13.2(19.0)$ & $10.6(17.7)$ \\
\hline Reaction times - congruent & $732(265)$ & $639(169)$ & $697(223)$ & $637(164)$ \\
\hline Reaction times - incongruent & $772(302)$ & $674(184)$ & $744(282)$ & $669(157)$ \\
\hline
\end{tabular}

\section{Scores}

Language and Literature $\quad 7.42(1.55) \quad 7.74(1.55) \quad 7.42(1.57) \quad 7.30(1.64)$ 


$\begin{array}{lllll}\text { Mathematics } & 7.38(1.77) & 7.39(1.83) & 7.26(1.72) & 7.31(1.66) \\ \text { Social Sciences } & 7.33(1.89) & 7.72(1.70) & 7.60(1.77) & 7.39(1.74) \\ \text { Natural Sciences } & 7.35(1.72) & 7.80(1.70) & 7.49(1.57) & 7.36(1.72)\end{array}$

*Note. Standard deviations are in parentheses.

To check if the training had an effect on EF tasks and questionnaires and on academic performance, a separate ANOVA was performed for each specific subcomponent of each task, taking into account the Time factor (pre-test, post-test) and the Group (experimental, control) (see Figure 2 for visual representation of the main effects).

In the CHEXI working memory scale, statistical differences were observed regarding Time [F $(1,711)=4.31, p=0.038, \eta^{2}$ partial $\left.=0.01\right]$ and a significant interaction between Time and Group $\left[\mathrm{F}(1,711)=14.66, \mathrm{p}=<0.001, \eta^{2}\right.$ partial $\left.=0.02\right]$. Through the post hoc analysis with Tukey's correction, it was demonstrated in the experimental group that there was a significant difference of 1.33 points between the pre-test and post-test $[\mathrm{t}=4.33, \mathrm{p}<0.001]$, while, on the other hand, in the control group no differences were found between the pre-test and the post-test $[\mathrm{t}=-1.20, \mathrm{p}=$ 0.628]. In other words, the trained group improved their working memory scores relative to the control group.

In the CHEXI inhibition scale, significant differences were also observed as a function of the Time factor $\left[F(1,711)=21.18, p<0.001, \eta^{2}\right.$ partial $\left.=0.03\right]$, as well as a significant interaction between Time and Group $\left[\mathrm{F}(1,711)=5.40, \mathrm{p}=0.020, \eta^{2}\right.$ partial $\left.=0.01\right]$. The trained group showed a significant difference of 1.51 points between the pre-test and post-test $[t=5.08, p<0.001]$ while, on the other hand, in the control group no differences were found $[\mathrm{t}=1.56, \mathrm{p}=0.404]$.

Regarding the flanker task, ANOVAs were performed taking into account the percentage of errors and the reaction times of the participants in each condition, after eliminating the outlier values that differed by more than 2.5 standard deviations from the mean per subject and condition. In both analyses, the factors of Congruency (congruent, incongruous), Time (pre-test, post-test) and Group (experimental, control) were included. Regarding the percentage of errors, a significant effect of the Congruency factor $\left[F(1,711)=414.48, p<0.001, \eta^{2}\right.$ partial $\left.=0.37\right]$ was found, showing a higher 
percentage of errors in the incongruous trials than in the congruent ones, but no significant effect of Time was found $[\mathrm{F}(1,711)=0.25, \mathrm{p}=0.614]$, nor any interaction between the factors $[\mathrm{Fs}<1$, $\mathrm{ps}>0.40]$. Regarding reaction times, both groups significantly improved their response times from the pre-test to the post-test $\left[F(1,593)=14.59, \mathrm{p}<0.001, \eta^{2}\right.$ partial $\left.=0.02\right]$, and a general congruence effect was also obtained $\left[F(1,593)=172.98, p<0.001, \eta^{2}\right.$ partial $\left.=0.23\right]$. The triple interaction was not significant $[\mathrm{F}(1,593)=2.48, \mathrm{p}=0.116]$.

Similar results were found in the Simon task. Regarding the percentage of errors, we found a significant effect of Congruency $\left[\mathrm{F}(1,711)=195.54, \mathrm{p}<0.001, \eta^{2}\right.$ partial $\left.=0.22\right]$, but we did not observe a significant effect of Time $[\mathrm{F}(1,711)=6.20, \mathrm{p}=0.013]$, nor a triple interaction that would suggest differential effects as a consequence of training $[F<1, p>0.40]$. Regarding reaction times, both groups increased their speed significantly from pre-test to post-test $[F(1,693)=67.98, p$ $<0.001, \eta^{2}$ partial $\left.=0.09\right]$, and also showed a generalized Congruency effect $[F(1,693)=106.93$, $\mathrm{p}<0.001, \eta^{2}$ partial $\left.=0.13\right]$. The triple interaction was not significant $[\mathrm{F}<1, \mathrm{p}>0.98]$.

Regarding academic performance, the grades obtained by the students changed significantly as a function of the Time factor, improving from the pre-test to the post-test $[F(1,669)=16.13, p$ $<0.001, \eta^{2}$ partial $\left.=0.02\right]$. Significant differences were found between the scores in the different subjects $\left[\mathrm{F}(3,2007)=8.45, \mathrm{p}<0.001, \eta^{2}\right.$ partial $\left.=0.01\right]$, showing different mean values of academic performance depending on each of them. Importantly, the triple interaction between Time, Group and Subject was significant $\left[\mathrm{F}(3,2007)=17.68, \mathrm{p}<0.001, \eta^{2}\right.$ partial $\left.=0.03\right]$. Post hoc analyses with Tukey's correction for multiple comparisons showed that computerized training significantly improved the scores of the experimental group in the subjects of Language and Literature ( 0.32 points out of 10 ), Social Sciences ( 0.39 points) and Natural Sciences ( 0.45 points; all ps $<0.001$ ), but not in the subject of Mathematics. On the other hand, in the control group there were no significant differences in the scores of the four subjects analyzed between the pre-test and the posttest. These results suggest that, through the CTP, the students of the experimental group improved their academic performance compared to the control group.

Figure 2. Estimated marginal means by group in the pre-test (grey lines) and post-test (black lines) for the significant effects. Error bars represent 95\% confidence intervals. Note: Lower 

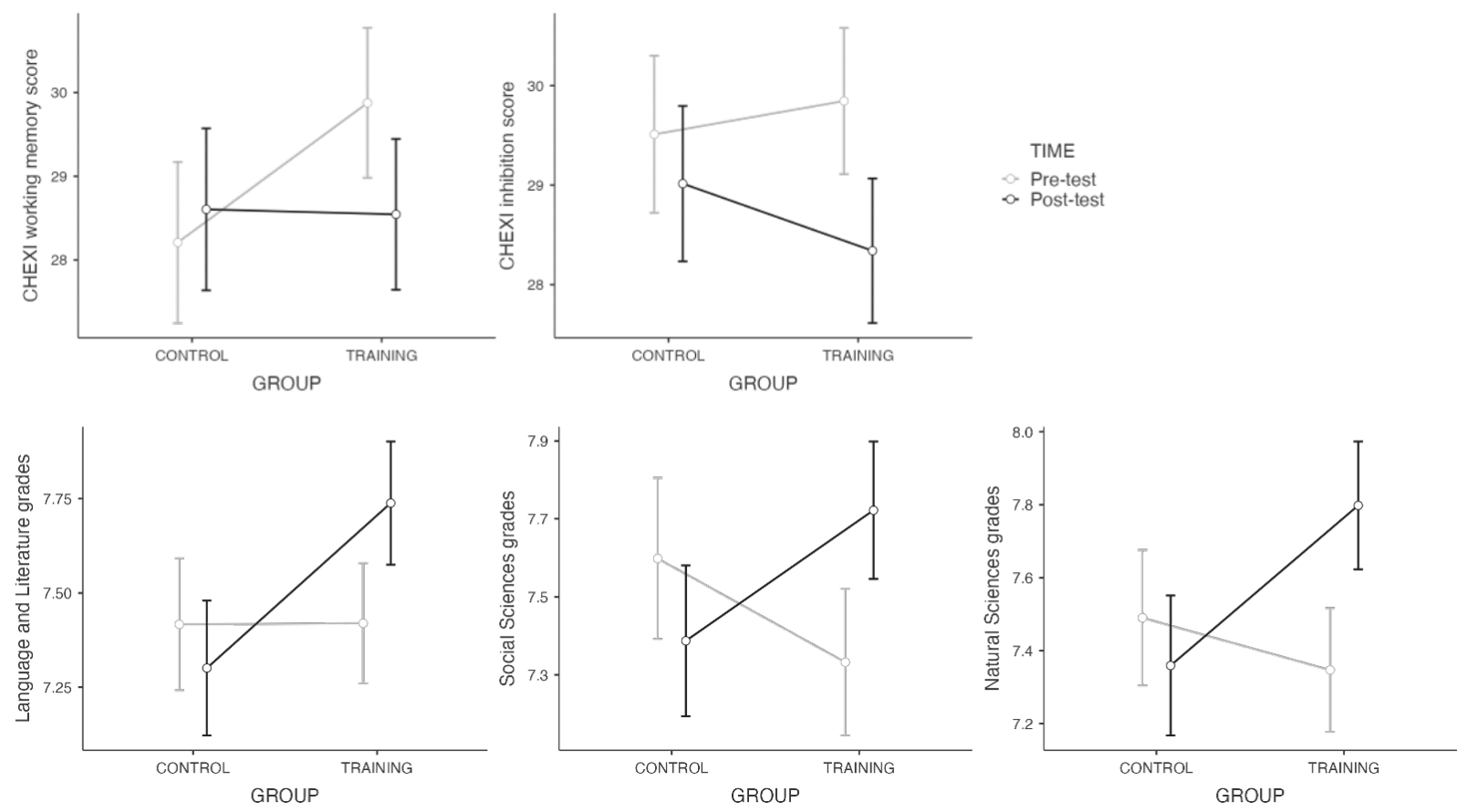

\section{Discussion}

In the present study, we analyze the effects derived from a CTP carried out in the classroom on the improvement of executive functions and academic performance in a sample of Spanish primary school students. The results indicated that the students who participated in the CTP improved the scores obtained in the executive functions questionnaire and in academic performance compared to the control group. However, in two chronometric tests classically linked to the study of inhibition (flankers and Simon tasks), no significant differences were obtained.

First, our results showed a significant effect of the CTP in relation to the children's working memory scores obtained from the families using a validated questionnaire. These findings are in line with the results presented in the recent meta-analysis carried out by Cao et al., (2020) where they indicated that the effects of CTP and its transfer effect to working memory were the most highly significant of the three main executive functions explored. Regarding the inhibition 
subscale, at the end of the 8-week intervention, a significant improvement was also observed in the experimental group. These results seem to be in line with other recent studies that demonstrate a possible improvement in inhibition through a CTP (Blakey \& Carroll, 2015; Sánchez-Pérez et al., 2018).

Second, it is worth noting that these differences were not replicated in the chronometric tasks that were also used, and, despite observing an improvement from pre-test to post-test in reaction times and the percentage of errors in the flanker task and in the Simon task, no significant differences were found between the two groups. Thus, the results shown differ between the scores obtained in the questionnaire and the Flankers and Simon tasks, corroborating once again the complexity involved in measuring inhibition and, more specifically, the relationship between the behavioral questionnaires and the chronometric performance tests (Burgess et al., 2006; Toplak et al., 2013). In light of these findings, it is possible to suppose that, although the processes explored may share the same neuroanatomical substrate, the two types of measures can evaluate different aspects of the same construct. While the CHEXI appears to measure the behavioral component of EF, the chronometric performance tests appear to measure the cognitive component (Anderson, 2002). The chronometric measures can represent the students' abilities to demonstrate their EF in a highly structured environment and/or activity (such as a laboratory test), while the scores obtained in questionnaires such as the CHEXI can represent the observable behaviors associated with that EF in everyday settings, such as the classroom (see Thorell \& Nyberg, 2008).

In our study, while very strong correlations were observed between the results of both CHEXI scales (working memory and inhibition) both in the pre-test and in the post-test (with rs $>.71$ ), the correlations of these scales with the effects (incongruous minus congruent) in the reaction times of the Simon and flanker chronometric tasks were markedly low (with rs $<.10$ in all contrasts, both at pre-test and post-test). Similar results were observed in a sample of 844 American preschoolers (Camerota et al., 2018). Furthermore, and despite the existing relationship between the CHEXI subscales, the results of the comparisons between the incongruity indices of the two chronometric tasks showed an absence of correlation (with rs <.05). Similar effects highlighting the scarce convergence of results between chronometric tasks that have traditionally been used to measure inhibition components have already been previously described in the literature (see Paap \& Sawi, 2014), and our results coincide with this vision. Therefore, our findings suggest the importance of 
combining the two types of measurement in order to be able to collect more complete information regarding the evaluation, intervention, and improvement of students' EFs (Toplak et al., 2009, 2013).

Consistent with the literature, in our study a significant high correlation was found between the scores of the two subscales of the CHEXI (working memory and inhibition) and the grades of the students in the subjects of Language and Literature, Mathematics, Social Sciences, and Natural Sciences. The working memory subscale is the one that obtained the strongest correlations with the aforementioned scores, both in the pre-test (with -.43<rs <-. 38) and in the post-test (with -.47 $<$ rs <-. 41). In contrast, the correlations between the inhibition subscale and scores were substantially lower (with -.30<rs <-. 37), albeit significant. These results coincide with those described in the literature, reinforcing the link between working memory and academic performance (Carretti et al., 2009; Friso-van den Bos et al., 2013; Mahone et al., 2002; McAuley et al., 2010; St Clair-Thompson \& Gathercole, 2006; Van der Ven et al., 2012) and they highlight the predictive utility of CHEXI to measure EF in students (Thorell \& Nyberg, 2008; Thorell et al., 2013).

Finally, and especially relevant, our results revealed a clear-cut improvement in the academic performance of students who completed the CTP. These results are in line with other recent studies (Sánchez-Pérez et al., 2018). In our case, the improvements took place in the subjects related to language and sciences, suggesting a significant contribution of the CTP in learning in a school context. There are numerous studies that corroborate the direct relationship between executive functions and academic performance (Ahmed et al., 2019; Best et al., 2011; Cortés et al., 2019; Gordon et al., 2018). This improvement of EF also has an indirect and reciprocal relationship with other key aspects in learning and therefore in academic performance such as the verbal factor, logical reasoning (Best et al., 2011), problem solving, reasoning or planning (Collins \& Koechlin, 2012; Duncan et al., 2012), or skills related to reading (Borella et al., 2010; Butterfuss \& Kendeou, 2018; G. J. Duncan et al., 2007; for reviews, see Follmer, 2018; Gathercole et al., 2004).

However, despite the overall positive results in this study, these claims must be interpreted with caution. These results invite future experimental research to corroborate the effects and expand the study variables. We directed our tests to the assessment of working memory and inhibition skills, 
and considering the multifaceted construct of EF (Miyake et al., 2000), future studies should be aimed at exploring additional components, such as cognitive flexibility. Additionally, the fact that no significant intergroup differences were observed in the flanker and Simon tasks raises the question of the effectiveness of the program in relation to inhibitory control as a whole. In future research, the effects of this type of intervention programs could be analyzed through the inclusion of other ecological and rewarding evaluation measures of EFs carried out in the same classroom ( Morrison \& Grammer, 2016).

One aspect to consider for future studies is the magnification effect (Karbach \& Unger, 2014), which assumes that individuals with higher performance (in our case, students with typical development) will benefit more from cognitive interventions, since they have greater (in terms of quantity and efficiency) cognitive resources than those with lower basic performance (in our case, students with atypical development). In fact, a recent meta-analysis of 90 studies by Takacs \& Kassai, (2019) found that computerized training was more beneficial for children with normal development. In our study, students with atypical development were not included, and this is an aspect to work on in future studies in order to establish a higher level of inclusion.

In summary, following an optimal research design to analyze the possible results of a computerized training aimed at improving EFs (Cao et al., 2020; Diamond \& Ling, 2019), a positive association was found between training, executive functions, and academic performance. Our findings suggest that the improvements obtained in the subscales of working memory and inhibition, as well as in the academic performance of the students were specifically related to the type of intervention carried out. These results have practical implications for improving learning and academic success. 


\section{References}

Ackermann, S., Halfon, O., Fornari, E., Urben, S., \& Bader, M. (2018). Cognitive Working Memory Training (CWMT) in adolescents suffering from Attention-Deficit/Hyperactivity Disorder (ADHD): A controlled trial taking into account concomitant medication effects. Psychiatry Research, 269, 79-85. https://doi.org/10.1016/j.psychres.2018.07.036

Ahmed, S. F., Tang, S., Waters, N. E., \& Davis-Kean, P. (2019). Executive function and academic achievement: Longitudinal relations from early childhood to adolescence. Journal of Educational Psychology, 111(3), 446-458. https://doi.org/10.1037/edu0000296

Anderson, P. (2002). Assessment and Development of Executive Function (EF) During Childhood. Child Neuropsychology, 8(2), 71-82. https://doi.org/10.1076/chin.8.2.71.8724

Antón, E., Duñabeitia, J. A., Estévez, A., Hernández, J. A., Castillo, A., Fuentes, L. J., Davidson, D. J., \& Carreiras, M. (2014). Is there a bilingual advantage in the ANT task? Evidence from children. Frontiers in Psychology, 5, 398. https://doi.org/10.3389/fpsyg.2014.00398

Anwyl-Irvine, A. L., Massonnié, J., Flitton, A., Kirkham, N., \& Evershed, J. K. (2020). Gorilla in our midst: An online behavioral experiment builder. Behavior Research Methods, 52(1), 388-407. https://doi.org/10.3758/s13428-019-01237-x

Baddeley, A. D., \& Hitch, G. J. (1994). Developments in the concept of working memory. Neuropsychology, 8(4), 485-493. https://doi.org/10.1037/0894-4105.8.4.485

Best, J. R., Miller, P. H., \& Naglieri, J. A. (2011). Relations between Executive Function and Academic Achievement from Ages 5 to 17 in a Large, Representative National Sample. Learning and Individual Differences, 21(4), 327-336. https://doi.org/10.1016/j.lindif.2011.01.007

Bierman, K. L., Nix, R. L., Greenberg, M. T., Blair, C., \& Domitrovich, C. E. (2008). Executive 
functions and school readiness intervention: Impact, moderation, and mediation in the Head Start REDI program. Development and Psychopathology, 20(3), 821-843.

https://doi.org/10.1017/S0954579408000394

Blair, C., \& Raver, C. C. (2015). School Readiness and Self-Regulation: A Developmental Psychobiological Approach. Annual review of psychology, 66, 711-731. https://doi.org/10.1146/annurev-psych-010814-015221

Blair, C., \& Razza, R. P. (2007). Relating Effortful Control, Executive Function, and False Belief Understanding to Emerging Math and Literacy Ability in Kindergarten. Child Development, 78(2), 647-663. https://doi.org/10.1111/j.1467-8624.2007.01019.x

Blakey, E., \& Carroll, D. J. (2015). A Short Executive Function Training Program Improves Preschoolers' Working Memory. Frontiers in Psychology, 0. https://doi.org/10.3389/fpsyg.2015.01827

Borella, E., Carretti, B., \& Pelegrina, S. (2010). The specific role of inhibition in reading comprehension in good and poor comprehenders. Journal of Learning Disabilities, 43(6), 541-552. https://doi.org/10.1177/0022219410371676

Bull, R., Espy, K. A., Wiebe, S. A., Sheffield, T. D., \& Nelson, J. M. (2011). Using confirmatory factor analysis to understand executive control in preschool children: Sources of variation in emergent mathematic achievement: Executive control and emergent mathematics. Developmental Science, 14(4), 679-692. https://doi.org/10.1111/j.1467-7687.2010.01012.x

Burgess, P. W., Alderman, N., Forbes, C., Costello, A., Coates, L. M.-A., Dawson, D. R., Anderson, N. D., Gilbert, S. J., Dumontheil, I., \& Channon, S. (2006). The case for the development and use of «ecologically valid» measures of executive function in experimental and clinical neuropsychology. Journal of the International Neuropsychological Society: JINS, 12(2), 194- 
209. https://doi.org/10.1017/S1355617706060310

Butterfuss, R., \& Kendeou, P. (2018). The Role of Executive Functions in Reading Comprehension. Educational Psychology Review, 30(3), 801-826. https://doi.org/10.1007/s10648-017-9422-6

Camerota, M., Willoughby, M. T., Kuhn, L. J., \& Blair, C. B. (2018). The Childhood Executive Functioning Inventory (CHEXI): Factor structure, measurement invariance, and correlates in US preschoolers. Child Neuropsychology: A Journal on Normal and Abnormal Development in Childhood and Adolescence, 24(3), 322-337. https://doi.org/10.1080/09297049.2016.1247795

Cao, Y., Huang, T., Huang, J., Xie, X., \& Wang, Y. (2020). Effects and Moderators of Computer-Based Training on Children's Executive Functions: A Systematic Review and Meta-Analysis. Frontiers in Psychology, 11. https://doi.org/10.3389/fpsyg.2020.580329

Carretti, B., Borella, E., Cornoldi, C., \& De Beni, R. (2009). Role of working memory in explaining the performance of individuals with specific reading comprehension difficulties: A meta-analysis. Learning and Individual Differences, 19(2), 246-251. https://doi.org/10.1016/j.lindif.2008.10.002

Cassotti, M., Agogué, M., Camarda, A., Houdé, O., \& Borst, G. (2016). Inhibitory Control as a Core Process of Creative Problem Solving and Idea Generation from Childhood to Adulthood. New Directions for Child and Adolescent Development, 2016(151), 61-72. https://doi.org/10.1002/cad.20153

Catale, C., Meulemans, T., \& Thorell, L. B. (2015). The childhood executive function inventory: Confirmatory factor analyses and cross-cultural clinical validity in a sample of 8- to 11-year-old children. Journal of Attention Disorders, 19(6), 489-495. https://doi.org/10.1177/1087054712470971

Collins, A., \& Koechlin, E. (2012). Reasoning, Learning, and Creativity: Frontal Lobe Function and 
Human Decision-Making. PLoS Biology, 10(3), e1001293.

https://doi.org/10.1371/journal.pbio.1001293

Cortés, A., Moyano Muñoz, N., \& Quílez Robres, A. (2019). The Relationship Between Executive Functions and Academic Performance in Primary Education: Review and Meta-Analysis. Frontiers in Psychology, 10. https://doi.org/10.3389/fpsyg.2019.01582

Davidson, M. C., Amso, D., Anderson, L. C., \& Diamond, A. (2006). Development of cognitive control and executive functions from 4 to 13 years: Evidence from manipulations of memory, inhibition, and task switching. Neuropsychologia, 44(11), 2037-2078. https://doi.org/10.1016/j.neuropsychologia.2006.02.006

D’Esposito, M., \& Postle, B. R. (2015). The Cognitive Neuroscience of Working Memory. Annual Review of Psychology, 66(1), 115-142. https://doi.org/10.1146/annurev-psych-010814-015031

Diamond, A. (2013). Executive Functions. Annual Review of Psychology, 64(1), 135-168. https://doi.org/10.1146/annurev-psych-113011-143750

Diamond, A. (2020). Executive functions. En Handbook of Clinical Neurology (Vol. 173, pp. 225-240). Elsevier. https://doi.org/10.1016/B978-0-444-64150-2.00020-4

Diamond, A., \& Lee, K. (2011). Interventions shown to Aid Executive Function Development in Children 4-12 Years Old. Science (New York, N.Y.), 333(6045), 959-964. https://doi.org/10.1126/science.1204529

Diamond, A., \& Ling, D. S. (2019). Review of the Evidence on, and Fundamental Questions About, Efforts to Improve Executive Functions, Including Working Memory. En A. Diamond \& D. S. Ling, Cognitive and Working Memory Training (pp. 143-431). Oxford University Press. https://doi.org/10.1093/oso/9780199974467.003.0008

Duncan, G. J., Dowsett, C. J., Claessens, A., Magnuson, K., Huston, A. C., Klebanov, P., Pagani, L. S., 
Feinstein, L., Engel, M., Brooks-Gunn, J., Sexton, H., Duckworth, K., \& Japel, C. (2007). School readiness and later achievement. Developmental Psychology, 43(6), 1428-1446. https://doi.org/10.1037/0012-1649.43.6.1428

Duncan, J., Schramm, M., Thompson, R., \& Dumontheil, I. (2012). Task rules, working memory, and fluid intelligence. Psychonomic Bulletin \& Review, 19(5), 864-870. https://doi.org/10.3758/s13423-012-0225-y

Engle, R. W., \& Kane, M. J. (2004). Executive Attention, Working Memory Capacity, and a Two-Factor Theory of Cognitive Control. En The psychology of learning and motivation: Advances in research and theory, Vol. 44 (pp. 145-199). Elsevier Science.

Eriksen, B. A., \& Eriksen, C. W. (1974). Effects of noise letters upon the identification of a target letter in a nonsearch task. Perception \& Psychophysics, 16(1), 143-149. https://doi.org/10.3758/BF03203267

Espinet, S. D., Anderson, J. E., \& Zelazo, P. D. (2013). Reflection training improves executive function in preschool-age children: Behavioral and neural effects. Developmental Cognitive Neuroscience, 4, 3-15. https://doi.org/10.1016/j.den.2012.11.009

Ferguson, H. J., Brunsdon, V. E. A., \& Bradford, E. E. F. (2021). The developmental trajectories of executive function from adolescence to old age. Scientific Reports, 11(1), 1382. https://doi.org/10.1038/s41598-020-80866-1

Follmer, D. J. (2018). Executive Function and Reading Comprehension: A Meta-Analytic Review. Educational Psychologist, 53(1), 42-60. https://doi.org/10.1080/00461520.2017.1309295

Friso-van den Bos, I., van der Ven, S. H. G., Kroesbergen, E. H., \& van Luit, J. E. H. (2013). Working memory and mathematics in primary school children: A meta-analysis. Educational Research Review, 10, 29-44. https://doi.org/10.1016/j.edurev.2013.05.003 
Gathercole, S. E., Pickering, S. J., Knight, C., \& Stegmann, Z. (2004). Working memory skills and educational attainment: Evidence from national curriculum assessments at 7 and 14 years of age. Applied Cognitive Psychology, 18(1), 1-16. https://doi.org/10.1002/acp.934

Gogtay, N., Giedd, J. N., Lusk, L., Hayashi, K. M., Greenstein, D., Vaituzis, A. C., Nugent, T. F., Herman, D. H., Clasen, L. S., Toga, A. W., Rapoport, J. L., \& Thompson, P. M. (2004). Dynamic mapping of human cortical development during childhood through early adulthood. Proceedings of the National Academy of Sciences, 101(21), 8174-8179. https://doi.org/10.1073/pnas.0402680101

Gordon, R., Smith-Spark, J. H., Newton, E. J., \& Henry, L. A. (2018). Executive Function and Academic Achievement in Primary School Children: The Use of Task-Related Processing Speed. Frontiers in Psychology, 9, 582. https://doi.org/10.3389/fpsyg.2018.00582

Hackman, D. A., Gallop, R., Evans, G. W., \& Farah, M. J. (2015). Socioeconomic status and executive function: Developmental trajectories and mediation. Developmental Science, 18(5), 686-702. https://doi.org/10.1111/desc.12246

Houdé, O., \& Borst, G. (2015). Evidence for an inhibitory-control theory of the reasoning brain. Frontiers in Human Neuroscience, 9, 148. https://doi.org/10.3389/fnhum.2015.00148

Karbach, J., \& Unger, K. (2014). Executive control training from middle childhood to adolescence. Frontiers in Psychology, 5, 390. https://doi.org/10.3389/fpsyg.2014.00390

Kassai, R., Futo, J., Demetrovics, Z., \& Takacs, Z. K. (2019). A meta-analysis of the experimental evidence on the near- and far-transfer effects among children's executive function skills. Psychological Bulletin, 145(2), 165-188. https://doi.org/10.1037/bul0000180

Kent, P. L. (2016). Working Memory: A Selective Review. Applied Neuropsychology: Child, 5(3), 163172. https://doi.org/10.1080/21622965.2016.1167491 
Klingberg, T. (2010). Training and plasticity of working memory. Trends in Cognitive Sciences, 14(7), 317-324. https://doi.org/10.1016/j.tics.2010.05.002

Kraus, T. H.-, \& Breznitz, Z. (2009). Can the Error Detection Mechanism Benefit from Training the Working Memory? A Comparison between Dyslexics and Controls - An ERP Study. PLoS ONE, 4(9), e7141. https://doi.org/10.1371/journal.pone.0007141

Last, B. S., Lawson, G. M., Breiner, K., Steinberg, L., \& Farah, M. J. (2018). Childhood socioeconomic status and executive function in childhood and beyond. PLOS ONE, 13(8), e0202964. https://doi.org/10.1371/journal.pone.0202964

Lubin, A., Vidal, J., Lanoë, C., Houdé, O., \& Borst, G. (2013). Inhibitory control is needed for the resolution of arithmetic word problems: A developmental negative priming study. Journal of Educational Psychology, 105(3), 701-708. https://doi.org/10.1037/a0032625

Mahone, E. M., Cirino, P. T., Cutting, L. E., Cerrone, P. M., Hagelthorn, K. M., Hiemenz, J. R., Singer, H. S., \& Denckla, M. B. (2002). Validity of the behavior rating inventory of executive function in children with ADHD and/or Tourette syndrome. Archives of Clinical Neuropsychology: The Official Journal of the National Academy of Neuropsychologists, 17(7), 643-662.

McAuley, T., Chen, S., Goos, L., Schachar, R., \& Crosbie, J. (2010). Is the behavior rating inventory of executive function more strongly associated with measures of impairment or executive function? Journal of the International Neuropsychological Society: JINS, 16(3), 495-505. https://doi.org/10.1017/S1355617710000093

Melby-Lervåg, M., Redick, T. S., \& Hulme, C. (2016). Working Memory Training Does Not Improve Performance on Measures of Intelligence or Other Measures of "Far Transfer": Evidence From a Meta-Analytic Review. Perspectives on Psychological Science, 11(4), 512-534.

https://doi.org/10.1177/1745691616635612 
Miyake, A., \& Friedman, N. P. (2012). The Nature and Organization of Individual Differences in Executive Functions: Four General Conclusions. Current Directions in Psychological Science, 21(1), 8-14. https://doi.org/10.1177/0963721411429458

Miyake, A., Friedman, N. P., Emerson, M. J., Witzki, A. H., Howerter, A., \& Wager, T. D. (2000). The Unity and Diversity of Executive Functions and Their Contributions to Complex "Frontal Lobe" Tasks: A Latent Variable Analysis. Cognitive Psychology, 41(1), 49-100. https://doi.org/10.1006/cogp.1999.0734

Moffitt, T. E., Arseneault, L., Belsky, D., Dickson, N., Hancox, R. J., Harrington, H., Houts, R., Poulton, R., Roberts, B. W., Ross, S., Sears, M. R., Thomson, W. M., \& Caspi, A. (2011). A gradient of childhood self-control predicts health, wealth, and public safety. Proceedings of the National Academy of Sciences, 108(7), 2693-2698. https://doi.org/10.1073/pnas.1010076108

Morris, P., Millenky, M., Raver, C. C., \& Jones, S. M. (2013). Does a Preschool Social and Emotional Learning Intervention Pay Off for Classroom Instruction and Children's Behavior and Academic Skills? Evidence From the Foundations of Learning Project. Early Education and Development, 24(7), 1020-1042. https://doi.org/10.1080/10409289.2013.825187

Morrison, A. B., \& Chein, J. M. (2011). Does working memory training work? The promise and challenges of enhancing cognition by training working memory. Psychonomic Bulletin \& Review, 18(1), 46-60. https://doi.org/10.3758/s13423-010-0034-0

Morrison, F. J., \& Grammer, J. K. (2016). Conceptual clutter and measurement mayhem: Proposals for cross-disciplinary integration in conceptualizing and measuring executive function. En Executive function in preschool-age children: Integrating measurement, neurodevelopment, and translational research (pp. 327-348). American Psychological Association.

https://doi.org/10.1037/14797-015 
Oberste, M., Javelle, F., Sharma, S., Joisten, N., Walzik, D., Bloch, W., \& Zimmer, P. (2019). Effects and Moderators of Acute Aerobic Exercise on Subsequent Interference Control: A Systematic Review and Meta-Analysis. Frontiers in Psychology, 10, 2616.

https://doi.org/10.3389/fpsyg.2019.02616

Paap, K. R., \& Sawi, O. (2014). Bilingual advantages in executive functioning: Problems in convergent validity, discriminant validity, and the identification of the theoretical constructs. Frontiers in Psychology, 5, 962. https://doi.org/10.3389/fpsyg.2014.00962

Pandey, A., Hale, D., Das, S., Goddings, A.-L., Blakemore, S.-J., \& Viner, R. M. (2018). Effectiveness of Universal Self-regulation-Based Interventions in Children and Adolescents: A Systematic Review and Meta-analysis. JAMA Pediatrics, 172(6), 566.

https://doi.org/10.1001/jamapediatrics.2018.0232

Peretz, C., Korczyn, A. D., Shatil, E., Aharonson, V., Birnboim, S., \& Giladi, N. (2011). ComputerBased, Personalized Cognitive Training versus Classical Computer Games: A Randomized Double-Blind Prospective Trial of Cognitive Stimulation. Neuroepidemiology, 36(2), 91-99. https://doi.org/10.1159/000323950

Preiss, M., Shatil, E., Čermáková, R., Cimermanová, D., \& Ram, I. (2013). Personalized Cognitive Training in Unipolar and Bipolar Disorder: A Study of Cognitive Functioning. Frontiers in Human Neuroscience, 7. https://doi.org/10.3389/fnhum.2013.00108

Prins, P. J. M., Brink, E. T., Dovis, S., Ponsioen, A., Geurts, H. M., de Vries, M., \& van der Oord, S. (2013). “Braingame Brian”: Toward an Executive Function Training Program with Game Elements for Children with ADHD and Cognitive Control Problems. Games for Health Journal, 2(1), 44-49. https://doi.org/10.1089/g4h.2013.0004

Raver, C. C., Jones, S. M., Li-Grining, C., Zhai, F., Bub, K., \& Pressler, E. (2011). CSRP's Impact on 
Low-Income Preschoolers' Preacademic Skills: Self-Regulation as a Mediating Mechanism: CSRP's Impact on Low-Income Preschoolers' Preacademic Skills. Child Development, 82(1), 362-378. https://doi.org/10.1111/j.1467-8624.2010.01561.x

Rosen, M. L., Sheridan, M. A., Sambrook, K. A., Meltzoff, A. N., \& McLaughlin, K. A. (2018). Socioeconomic disparities in academic achievement: A multi-modal investigation of neural mechanisms in children and adolescents. NeuroImage, 173, 298-310. https://doi.org/10.1016/j.neuroimage.2018.02.043

Rueda, M. R., Fan, J., McCandliss, B. D., Halparin, J. D., Gruber, D. B., Lercari, L. P., \& Posner, M. I. (2004). Development of attentional networks in childhood. Neuropsychologia, 42(8), 1029-1040. https://doi.org/10.1016/j.neuropsychologia.2003.12.012

Ryan, R. M., \& Deci, E. L. (2000). Self-determination theory and the facilitation of intrinsic motivation, social development, and well-being. American Psychologist, 55(1), 68-78. https://doi.org/10.1037/0003-066X.55.1.68

Sánchez-Pérez, N., Fuentes, L. J., Eisenberg, N., \& González-Salinas, C. (2018). Effortful control is associated with children's school functioning via learning-related behaviors. Learning and Individual Differences, 63, 78-88. https://doi.org/10.1016/j.lindif.2018.02.009

Schwaighofer, M., Fischer, F., \& Bühner, M. (2015). Does Working Memory Training Transfer? A Meta-Analysis Including Training Conditions as Moderators. Educational Psychologist, 50(2), 138-166. https://doi.org/10.1080/00461520.2015.1036274

Sesma, H. W., Mahone, E. M., Levine, T., Eason, S. H., \& Cutting, L. E. (2009). The Contribution of Executive Skills to Reading Comprehension. Child Neuropsychology, 15(3), 232-246. https://doi.org/10.1080/09297040802220029

Shah, T. M., Weinborn, M., Verdile, G., Sohrabi, H. R., \& Martins, R. N. (2017). Enhancing Cognitive 
Functioning in Healthly Older Adults: A Systematic Review of the Clinical Significance of Commercially Available Computerized Cognitive Training in Preventing Cognitive Decline. Neuropsychology Review, 27(1), 62-80. https://doi.org/10.1007/s11065-016-9338-9

Shatil, E. (2013). Does combined cognitive training and physical activity training enhance cognitive abilities more than either alone? A four-condition randomized controlled trial among healthy older adults. Frontiers in Aging Neuroscience, 5. https://doi.org/10.3389/fnagi.2013.00008

Simon, J. R., \& Rudell, A. P. (1967). Auditory S-R compatibility: The effect of an irrelevant cue on information processing. Journal of Applied Psychology, 51(3), 300-304. https://doi.org/10.1037/h0020586

Smid, C. R., Karbach, J., \& Steinbeis, N. (2020). Toward a Science of Effective Cognitive Training. Current Directions in Psychological Science, 29(6), 531-537. https://doi.org/10.1177/0963721420951599

Spencer-Smith, M., \& Klingberg, T. (2015). Benefits of a Working Memory Training Program for Inattention in Daily Life: A Systematic Review and Meta-Analysis. PLOS ONE, 10(3), e0119522. https://doi.org/10.1371/journal.pone.0119522

Spierer, L., Chavan, C. F., \& Manuel, A. L. (2013). Training-induced behavioral and brain plasticity in inhibitory control. Frontiers in Human Neuroscience, 7. https://doi.org/10.3389/fnhum.2013.00427

St Clair-Thompson, H., \& Gathercole, S. (2006). Executive function and achievements in school: Shifting, updating, inhibition, and working memory. Quarterly journal of experimental psychology (2006), 59, 745-759. https://doi.org/10.1080/17470210500162854

Takacs, Z. K., \& Kassai, R. (2019). The efficacy of different interventions to foster children's executive function skills: A series of meta-analyses. Psychological Bulletin, 145(7), 653-697. 
https://doi.org/10.1037/bul0000195

Tapia, J. L., \& Duñabeitia, J. A. (2021). Improving Language Acquisition and Processing With Cognitive Stimulation. Frontiers in Psychology, 0. https://doi.org/10.3389/fpsyg.2021.663773

Thorell, L. B., \& Nyberg, L. (2008). The Childhood Executive Functioning Inventory (CHEXI): A New Rating Instrument for Parents and Teachers. Developmental Neuropsychology, 33(4), 536-552. https://doi.org/10.1080/87565640802101516

Thorell, L. B., Veleiro, A., Siu, A. F. Y., \& Mohammadi, H. (2013). Examining the relation between ratings of executive functioning and academic achievement: Findings from a cross-cultural study. Child Neuropsychology, 19(6), 630-638. https://doi.org/10.1080/09297049.2012.727792

Titz, C., \& Karbach, J. (2014). Working memory and executive functions: Effects of training on academic achievement. Psychological Research, 78(6), 852-868. https://doi.org/10.1007/s00426013-0537-1

Toplak, M. E., Bucciarelli, S. M., Jain, U., \& Tannock, R. (2009). Executive functions: Performancebased measures and the behavior rating inventory of executive function (BRIEF) in adolescents with attention deficit/hyperactivity disorder (ADHD). Child Neuropsychology: A Journal on Normal and Abnormal Development in Childhood and Adolescence, 15(1), 53-72. https://doi.org/10.1080/09297040802070929

Toplak, M. E., West, R. F., \& Stanovich, K. E. (2013). Practitioner review: Do performance-based measures and ratings of executive function assess the same construct? Journal of Child Psychology and Psychiatry, and Allied Disciplines, 54(2), 131-143. https://doi.org/10.1111/jcpp.12001

Van der Ven, S. H. G., Kroesbergen, E. H., Boom, J., \& Leseman, P. P. M. (2012). The development of executive functions and early mathematics: A dynamic relationship. The British Journal of 
Educational Psychology, 82(Pt 1), 100-119. https://doi.org/10.1111/j.2044-8279.2011.02035.x

Weerdmeester, J., Cima, M., Granic, I., Hashemian, Y., \& Gotsis, M. (2016). A Feasibility Study on the Effectiveness of a Full-Body Videogame Intervention for Decreasing Attention Deficit Hyperactivity Disorder Symptoms. Games for Health Journal, 5(4), 258-269. https://doi.org/10.1089/g4h.2015.0103

Wong, A. S. Y., He, M. Y. Q., \& Chan, R. W. S. (2014). Effectiveness of Computerized Working Memory Training Program in Chinese Community Settings for Children With Poor Working Memory. Journal of Attention Disorders, 18(4), 318-330.

https://doi.org/10.1177/1087054712471427

Yeniad, N., Malda, M., Mesman, J., van IJzendoorn, M. H., \& Pieper, S. (2013). Shifting ability predicts math and reading performance in children: A meta-analytical study. Learning and Individual Differences, 23, 1-9. https://doi.org/10.1016/j.lindif.2012.10.004

Zelazo, P. D., Anderson, J. E., Richler, J., Wallner-Allen, K., Beaumont, J. L., Conway, K. P., Gershon, R., \& Weintraub, S. (2014). NIH Toolbox Cognition Battery (CB): Validation of executive function measures in adults. Journal of the International Neuropsychological Society: JINS, 20(6), 620-629. https://doi.org/10.1017/S1355617714000472

Zelazo, P. D., \& Carlson, S. M. (2012). Hot and Cool Executive Function in Childhood and Adolescence: Development and Plasticity. Child Development Perspectives, n/a-n/a. https://doi.org/10.1111/j.1750-8606.2012.00246.x

Zhao, X., Chen, L., \& Maes, J. H. R. (2018). Training and transfer effects of response inhibition training in children and adults. Developmental Science, 21(1), e12511. https://doi.org/10.1111/desc.12511 
